On the Determination of the Critical Volume

This content has been downloaded from IOPscience. Please scroll down to see the full text. 1892 Proc. Phys. Soc. London 12137

(http://iopscience.iop.org/1478-7814/12/1/307)

View the table of contents for this issue, or go to the journal homepage for more

Download details:

IP Address: 130.237.122.245

This content was downloaded on 09/09/2015 at 06:52

Please note that terms and conditions apply. 
The constants for the formula $\mathrm{D}=\mathrm{A}+a t$ are :-

\begin{tabular}{|c|c|c|c|}
\hline Substance. & & A. & a. \\
\hline Methyl Formate & & $\cdot 5025$ & -.0007155 \\
\hline Acetate & & $\cdot 4839$ & 40 \\
\hline Formate & & $\cdot 4759$ & 06490 \\
\hline & & $\cdot 4644$ & 06250 \\
\hline Methyl Propionate & & $\cdot 4721$ & -.000621 \\
\hline
\end{tabular}

The critical densities of the five esters, obtained by the method of diameters, are :-

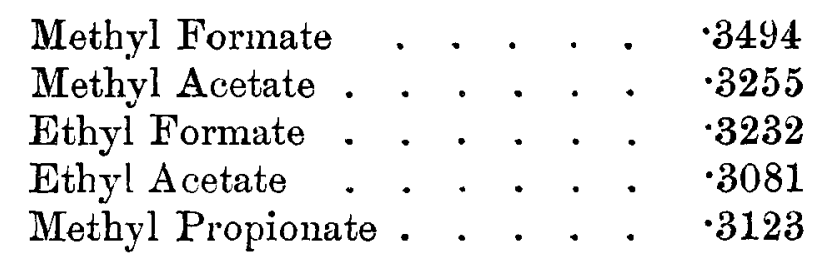

From the differences between the observed and calculated mean densities it may be concluded that, though there may be in some cases a slight indication of curvature, it is far too small to affect the determination of the critical densities of these substances.

\section{On the Determination of the Critical Volume.}

By Sydney Young, D.Sc., University College, Bristol*.

AвоUт a year ago I read a paper before the Physical Society $\dagger$ on the "Generalizations of Van der Waals regarding Corresponding Temperatures, Pressures, and Volumes ;" and at the close of the paper, after calling attention to the extreme difficulty attending the determination of the critical volume, I described a method by which the relative critical volumes of various substances could be ascertained. At that time it appeared to me that the direct determinations of the critical volumes of benzene, fluorbenzene, chlorobenzene, and acetic acid were probably approximately correct; and I was supported in this view by the fact that the ratios of the observed volumes

* Read October 28, 1892.

† I'roc. Physical Soc. vol. xi. p. 233. 
to that of fluorbenzene were practically identical with the ratios obtained by the graphical method then described.

I therefore assumed that the observed critical molecular volume of fluorbenzene was correct, and calculated the volumes of the other substances from their ratios to that of fluorbenzene, and gave these values as the probable critical molecular volumes of the other eleren substances. It was observed, however, that the critical volumes of the three alcohols and of ether obtained by this method were considerably lower than those previously deduced by Dr. Ramsay and myself, and were also lower than those calculated by M. Guye (Compt. Rend. cxii. p. 1257). Finally, I pointed out that if these values are taken as correct it would appear that the ratio of the actual critical density to the theoretical (for a "perfect" gas) is for many substances about $4 \cdot 4$.

Since then, M. E. Mathias has shown (Compt. Rend. cxv. p. 35) that the critical densities of the substances referred to in my paper may be determined by the method described by MM. Cailletet and Mathias (Compt. Rend. cii. p. 1202, civ. p. 1563). The method has also been found by M. Amagat to give excellent results with carbon dioxide, and by Mr. G. L. Thomas and myself with five of the lower esters; and I have therefore much pleasure in acknowledging the correctness both of the method (except, perhaps, in the case of the alcohols) and of the critical densities calculated by M. Mathias, and I have no hesitation in accepting these values in place of those previously adopted.

$I$ have myself made an independent calculation of the critical densities of the twelve substances by this method, and the results $I$ bave obtained are practically identical (except in the case of the alcohols) with those given by M. Mathias.

The law of MM. Cailletet and Mathias may be described very briefly as follows:- The means of the densities of any substance in the state of liquid and of saturated vapour, when mapped against the temperature, fall on a straight line. I quite agree with M. Mathias that in the great majority of cases the verification of the law is perfect; but with the three alcohols, especially methyl alcohol, there appears to me to be very decided curvature, too pronounced to be neglected, 
and I think it must be admitted that these substances behave exceptionally in this as in many other respects.

M. Mathias admits that at low temperatures the alcohols cease to follow the law ; but he is satisfied with the agreement between the observed and calculated mean densities for a range of $200^{\circ}$ from the critical point. The constants employed by M. Mathias for ethyl alcohol can be ascertained from his paper, and I give below the mean densities calculated from these constants, together with those calculated from the observed molecular volumes given in my paper (loc. cit.).

The constants for the formula $\mathrm{D}=\mathrm{A}+\alpha t$ are :$\mathrm{A}=\cdot 4149, \quad \alpha=-\cdot 0005576, \quad t=$ temperature (Centigrade).

Means of Densities of Liquid and Saturated Vapour.

\begin{tabular}{|c|c|c|c|}
\hline $\begin{array}{l}\text { Temperature, } \\
\text { Centigrade. }\end{array}$ & Observed. & Calculated. & $\Delta \times 1000$ \\
\hline $\begin{array}{c}22 \cdot 4 \\
39 \cdot 45 \\
65 \cdot 75 \\
89 \cdot 7 \\
105 \cdot 55 \\
128 \cdot 1 \\
144 \cdot 65 \\
151 \cdot 65 \\
163 \cdot 8 \\
1 \times 7 \cdot 9 \\
206 \cdot 35 \\
221 \cdot 35 \\
229 \cdot 2 \\
234 \cdot 3 \\
238 \cdot 9 \\
243 \cdot 1\end{array}$ & $\begin{array}{l}.3937 \\
.3865 \\
.3749 \\
.3636 \\
.3560 \\
.3442 \\
.3350 \\
.3309 \\
.3240 \\
.3104 \\
.2998 \\
.2899 \\
.2850 \\
.2811 \\
.2781 \\
\ldots \ldots . .\end{array}$ & $\begin{array}{l}\cdot 4024 \\
\cdot 3929 \\
\cdot 3782 \\
\cdot 3649 \\
\cdot 3560 \\
\cdot 3435 \\
\cdot 3342 \\
\cdot 3303 \\
\cdot 32355 \\
\cdot 3101 \\
\cdot 2998 \\
\cdot 2915 \\
\cdot 2871 \\
\cdot 2843 \\
\cdot 2817 \\
\cdot 2793\end{array}$ & $\begin{array}{r}+87 \\
+64 \\
+33 \\
+16 \\
11 \\
-7 \\
-8 \\
-6 \\
-4 \\
-3 \\
+0 \\
+16 \\
+21 \\
+32 \\
+36\end{array}$ \\
\hline
\end{tabular}

From the above differences it will, I think, be concluded that there is considerable curvature of the "diameter" in the case of ethyl alcohol, and with methyl alcohol it would be still more marked.

I now give a revised table of the critical densities and volumes of the twelve substances, adding, for the sake of convenitnce, the critical temperatures and pressures. The critical densities are those calculated by M. Mathias ; but in the case of the alcohols I give also the values which I have 


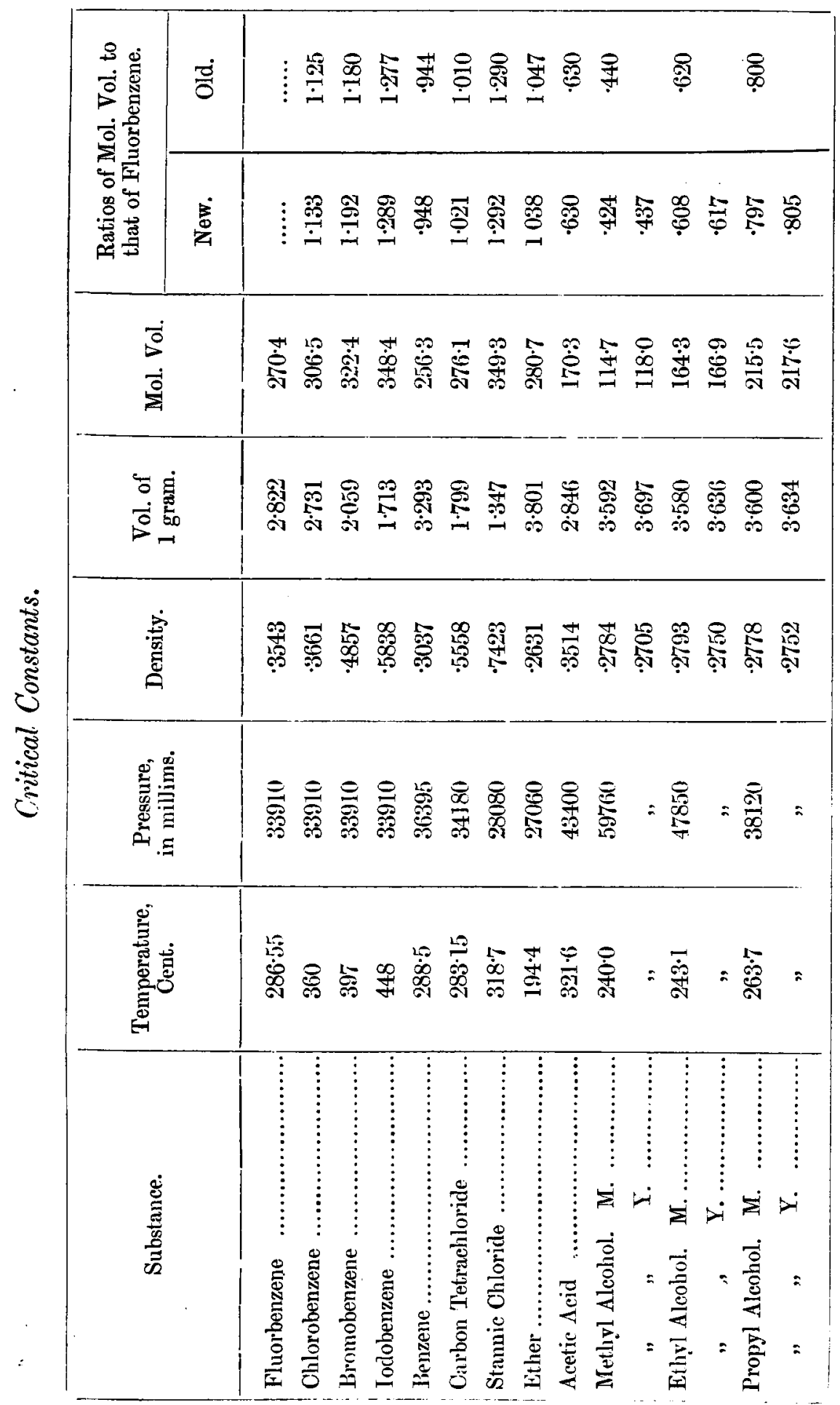


obtained by the same method, taking into account the curvature of the "diameter." The critical volumes of a gram and molecular volumes are calculated from the densities. The last two columns contain the ratios of the new critical molecular volumes to that of fluorbenzene, together with the ratios given on p. 184 of my previous paper and obtained by the graphical method there described. It will be seen that these ratios show satisfactory agreement.

As regards the alcohols it will be noticed that, if the curvature of the diameter is taken into account, the critical densities are lower and the volumes higher; also that the ratios of the critical molecular volumes to that of fluorbenzene agree better with those obtained by the graphical method.

It may be pointed out that if the generalizations of Van der Waals were strictly true, the angular coefficients $(\alpha)$ of the diameters of different substances should be directly proportional to their critical densities and inversely proportional to their absolute critical temperatures, or that for any substance

$$
\alpha=\text { const. } \times \frac{\mathrm{D}}{\mathrm{T}} ; \text { or } \frac{\alpha \mathrm{T}}{\mathrm{D}}=\text { const. }
$$

I have calculated the values of this "constant" for the substances mentioned in this paper (with the exception of methyl and propyl alcohol) and for the five esters studied by Mr. G. L. Thomas and myself.

\begin{tabular}{|c|c|c|c|c|c|}
\hline Substance. & $\frac{a \mathrm{~T}}{\mathrm{D}}$ & Substance. & $\frac{\alpha \mathrm{T}}{\mathrm{D}}$. & Substance. & $\frac{a \mathrm{~T}}{\bar{D}}$. \\
\hline lu & 932 & loride & .899 & $\mathrm{Me}$ & .997 \\
\hline & .95 & Sta & .988 & e & $1 \cdot 0$ \\
\hline e & .957 & $\mathrm{E} \mathrm{tl}$ & .972 & rmate & 061 \\
\hline zene & .957 & Ac & $\cdot 993$ & ate... & 055 \\
\hline enzene .... & .021 & Ethyl Alcohol * & 1.030 & Methyl Propionate & 1.02 \\
\hline
\end{tabular}

It can hardly be said that there is more than a rough approximation to constancy in the values of $\frac{\alpha T}{D}$.

I have recalculated the ratios of the actual to the theoretical critical densities, and the results are given in the following table :-

* M. Mathias' value of $a$. 


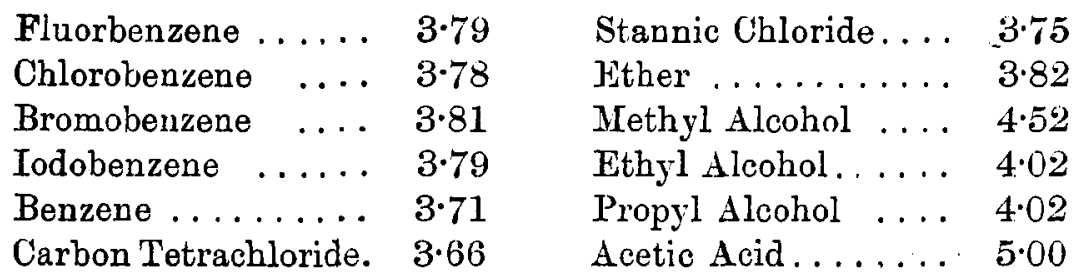

The first eight numbers agree fairly well; and it may be stated that for many substances the ratio of the actual critical density to the theoretical density (for a perfect gas) is about $3 \cdot 8$. The alcohols, notably methyl alcohol, and acetic acid, form exceptions to this law, and in the case of the esters the ratios (3.89 to 3.95$)$ are rather high.

VII. On the Boiling-points of different Liquids at Equal Pressures. By Sydney Young, D.Sc., Professor of Chemistry, University College, Bristol*.

EARLy in the present year, M. E. Colot (Compt. Rend. cxiv. p. 653) described a relation between the boilingpoints of any two liquids under equal pressures, which may be shortly described as follows.

If $t$ and $\theta$ are the temperatures of the two substances at any pressure, then

$$
t=\mathrm{A} \theta+\mathrm{B}
$$

where $A$ and $B$ are constants depending on the nature of the liquids.

The constants given by M. Colot refer to Centigrade temperatures, but for the purpose of this paper it is better to employ absolute temperatures. In this case A remains unaltered, but $B$ has a different value.

There are certain cases in which $B=0$ (for absolute temperatures), and the equation then becomes

$$
t=\mathrm{A} \theta \text { or } \frac{t}{\theta}=\mathrm{A} \text {. }
$$

This is identical with the equation given by Dr. Ramsay and myself (Phil. Mag. Jan. 1886, p. 33) for certain closely related substances such as ethyl chloride and bromide or chlorobenzene and bromobenzene, and I have shown that it holds good for the four halogen derivatives of benzene.

* Read October 28,1892 . 